\title{
Giant Lipoma of the Cheek: A Case Report
}

\author{
Dahi Mohamed El Moctar ${ }^{1 *}$, Ahmedou Moulaye Idriss ${ }^{2 *}$, Tfeil Yahya ${ }^{2}$, Lamine Keita1, \\ Mariem Aziza Sass ${ }^{1}$, Abdel Moumine' ${ }^{1}$, Cheich Sidi' ${ }^{1}$, Abdellahi Deddy ${ }^{1}$, \\ Ladour Abd El Vetah'
}

${ }^{1}$ Service ORL, Centre Hospitalier National, Nouakchott, Mauritanie

${ }^{2}$ Surgery Department Faculty of Medicine UNA, Nouakchott, Mauritanie

Email: *tardahi1@gmail.com, ${ }^{*}$ carcinologie@yahoo.fr

How to cite this paper: El Moctar, D.M., Idriss, A.M., Yahya, T., Keita, L., Sass, M.A., Moumine, A., Sidi, C., Deddy, A. and El Vetah, L.A. (2021) Giant Lipoma of the Cheek: A Case Report. Open Journal of Emergency Medicine, 9, 32-39. https://doi.org/10.4236/ojem.2021.92005

Received: April 5, 2021

Accepted: June 6, 2021

Published: June 9, 2021

Copyright $\odot 2021$ by author(s) and Scientific Research Publishing Inc. This work is licensed under the Creative Commons Attribution International License (CC BY 4.0).

http://creativecommons.org/licenses/by/4.0/

\begin{abstract}
Lipomas are the most common fatty mesenchymal tumors in the human body. They are very rare in the oral cavity. With a predilection, they have a rate of $1 \%$ to $4 \%$. We report the case of a 74 -year-old woman with a large painless lump on the left cheek of the mouth. This mass invading the deep spaces of the face induced a more difficult surgical excision.
\end{abstract}

\section{Keywords \\ Lipoma, Giant, Cheek, Mauritania}

\section{Introduction}

Lipomas are among the most common benign mesenchymal tumors in humans, which can occur in any region of the human body [1] [2]. They usually occur in the head and neck area; however, in the oral cavity, they are rare with $1 \%$ to $4 \%$ of all benign oral tumors [3]. These tumors are usually surrounded by a connective tissue capsule and often rest on a large pedicle; their growth is slow and painless, and their yellow color is sometimes visible through the mucosa when it is tight [4]. It has an incidence rate of about $1 \%-4 \%$ of all benign oral lesions, with a prevalence rate of about $0.0002 \%$. Specific anatomic locations of occurrence within the oral and maxillofacial region include the parotid region, buccal mucosa, lips, submandibular region, tongue, floor of the mouth, and palate [3]. Here we report the case of a 74-year-old patient who presented with a giant lipoma of the left cheek. She was operated on in the ENT and head and neck surgery department of the CHN in Nouakchott, Mauritania.

\section{Presentation of the Case}

This is a 74-year-old woman, received at the consultation of the Otorhinolaryn- 
gology and Cervico-Facial Surgery Department of the National Hospital Center of Nouakchott for swelling of the left cheek of the mouth that has been evolving for more than 8 years old.

The known diabetic patient followed and treated with insulin, mainly bothered by a large painless mass. Mass localized to the left cheek of the mouth, gradually increasing in size caused discomfort during chewing and talking. In addition, the patient also complained of tension in this region of the left cheek without paresthesia.

The sociodemograpic and clinical characteristics are summarized in Table 1.

On palpation, the mass was mobile from side to side and it was elastic, dense, painless, non-adherent to the cutaneous plane and with an extension to the level of the left temporal region, and measuring $20 \mathrm{~cm} \times 15 \mathrm{~cm}$, ranging from the lower edge of the left mandible to $1 \mathrm{~cm}$ in front of the left ear (Figure 1(a) and Figure 1(b)).

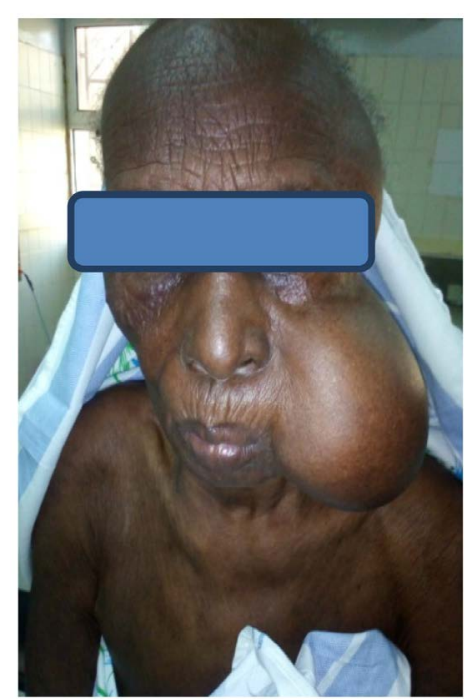

(a)

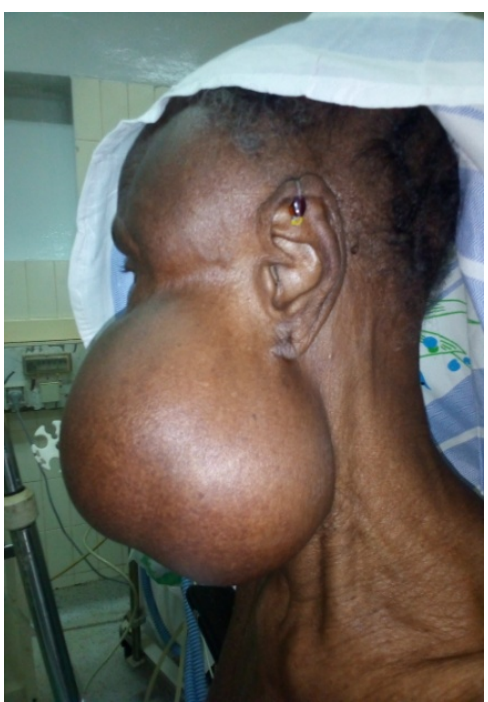

(b)

Figure 1. Giant lipoma of the left cheek invading the temporal region ((a): front; (b): profile view).

Table 1. Sociodemographic and clinical characteristics.

\begin{tabular}{cccc}
\hline Item & \multicolumn{3}{c}{ Result } \\
\hline Age & \multicolumn{3}{c}{74 years } \\
Sex & Female \\
Socioeconomic level & poor \\
Signs & Preoperatory & - \\
Trismus & + & - \\
Dysphagia & + & - \\
Disarticulation & + & - \\
Facial dysmorphism & + & \\
\end{tabular}


On the oral examination, the mass was palpable and non-fluctuating with a normal appearance of the mucosa opposite. The remainder of the ENT exam was unremarkable.

Facial Computed tomography found a voluminous fatty mass of the left face, with thin, regular boundaries enhanced after injection of contrast product and measuring $20 \mathrm{~cm} \times 13 \mathrm{~cm} \times 9 \mathrm{~cm}$. It extended to the infra-temporal and pterygomaxillary fossa, compressing the ipsilateral masticatory muscle, pushing the left pterygoid muscle and the left parotid gland posteriorly (Figure 2).

The mass was removed under general anesthesia through a horizontal incision of $10 \mathrm{~cm}$ in the length going with the major axis of the mass (Figure 3 ). Detachment of the upper and lower flaps was easy. The pathological tissue demonstrated was surrounded by a thin connective capsule and its coloration was distinctly yellow after the opening of the fascia, clearly differentiating from the surrounding tissue structures (Figure 4). The lesion was easily separated from the adjacent tissue. Following the cleavage plane, the mass has easily dissected from the infra-temporal and pterygopalatine fossae and ends in the pterygopalatine fossa (Figure 5(a) and Figure 5(b)). The arterial blood supply was from the pterygomaxillary artery and separated from the lesion by electro coagulation with bipolar forceps. The excision of the pterygopalatine part was difficult; a slight hemorrhage had occurred but was controlled a time by compression. The removal of the temporal part was performed through a second incision in the temporal region.

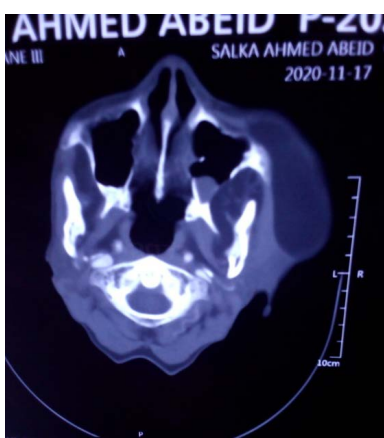

(a)

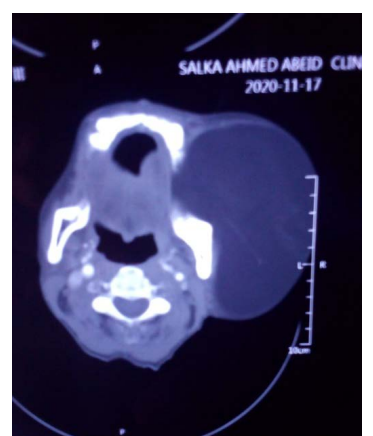

(b)

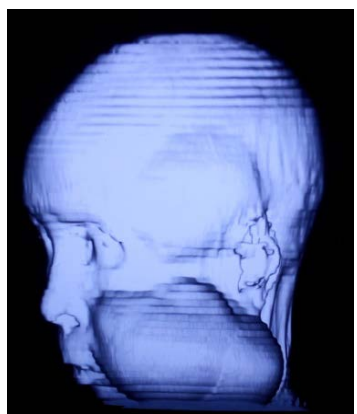

(c)

Figure 2. Tomodensitometry of the facial mass: axial cut ((a) and (b)) a voluminous fatty density of the left face, extended to the pterygomaxillary fossa. (c): Volumetric reconstruction image. 


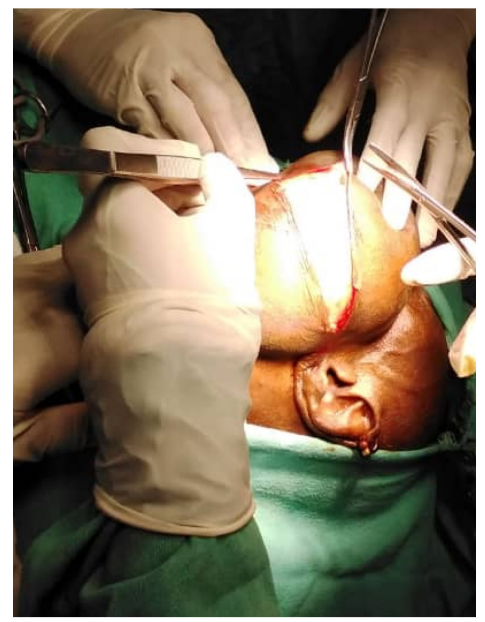

Figure 3. Incision on the major axis of the lipoma intraoperatively.

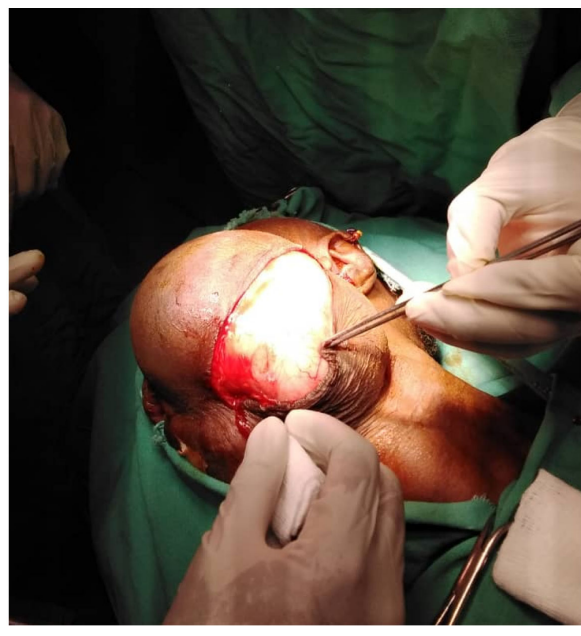

Figure 4. Yellowish appearance of the mass.

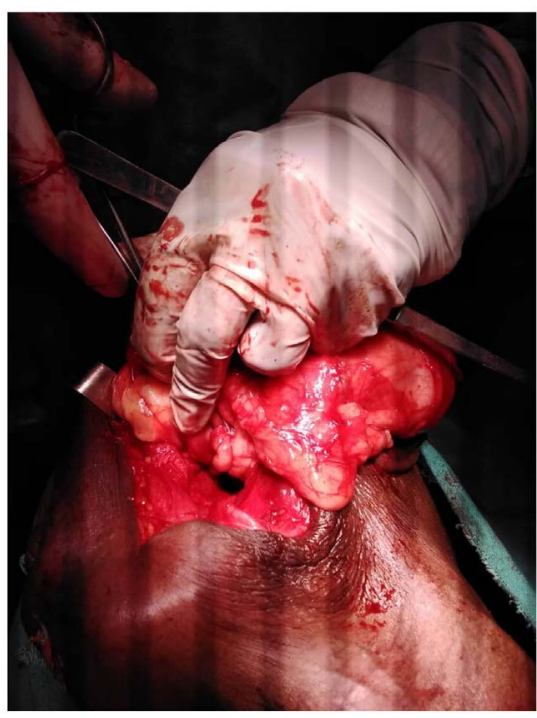

(a)

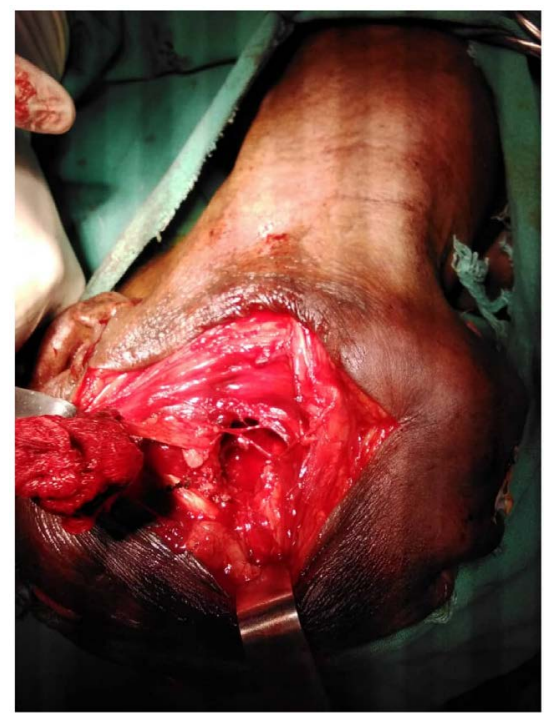

(b)

Figure 5. (a) and (b): Intraoperative view, dissection up to the pterygopalatine fossa. 
The surgical specimen removed, with a smooth and well-defined surface, measured $20 \mathrm{~cm}$ and showed clearly visible lobules and septa (Figure 6). Postoperative closure was achieved by separate stitches without remodeling

During the postoperative phase, the patient received antibiotic coverage for ten days (amoxicillin-clavulanic acid combination); analgesic treatment was provided by paracetamol. Wound disinfection was performed with $10 \%$ povidone iodine solution every other day.

\section{Outcome and follow-up:}

There were no postoperative complications. The patient was discharged after placing sutures and was called after a week for the removal of the sutures (Figure 7).

The patient was reviewed 6 weeks later and the clinical evaluation noted complete resolution of symptoms (Table 1 ).

The histo-pathological examination of the mass concluded the presence purely fatty tissue with normal excisional limits.

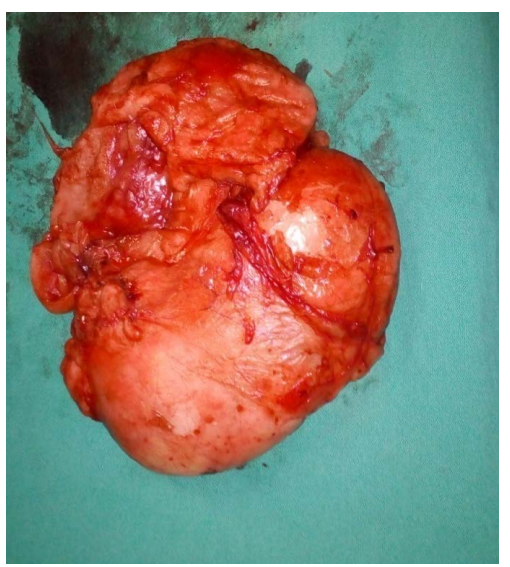

Figure 6. Surgical piece measuring $20 \mathrm{~cm}$.

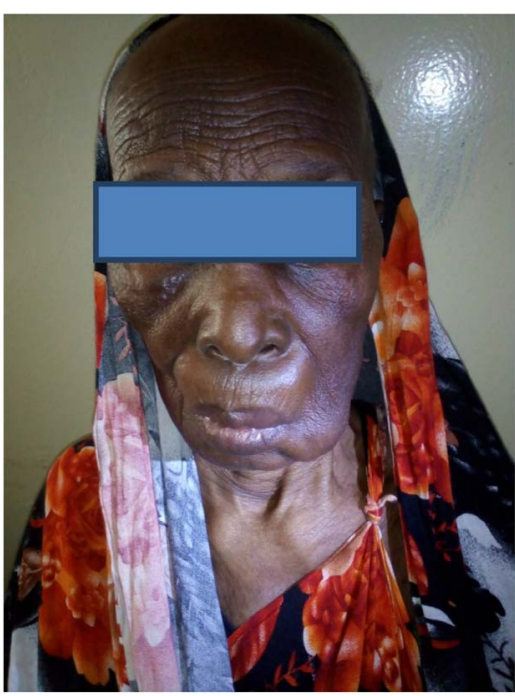

(a)

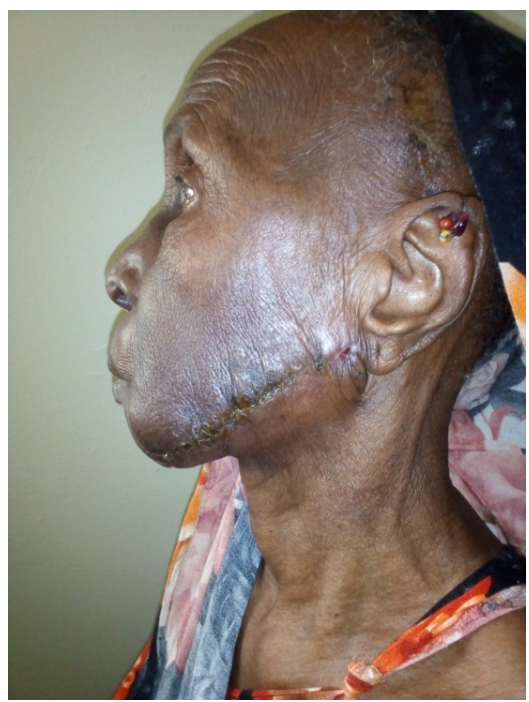

(b)

Figure 7. Removal of the sutures after Eight days ((a): front view; (b): profile view). 


\section{Discussion}

Lipomas are the benign tumor of mature adipose tissue. Near $20 \%$ are seen in the head and neck region and only $1 \%$ to $4 \%$ involve the oral cavity [3]. They affect individuals in the 4 th - 6th decades, the size rarely exceeds $25 \mathrm{~mm}$ [5], and has a slight male predilection [5] [6]. A few studies have reported an equal distribution between the sexes [7] [8]. In addition, a case of cellular angiolipoma infiltrating the cheek in a 9 months old infant has been reported [9]. Clinically, intraoral lipomas are generally slowed growing and asymptomatic. However, few reports associate intraoral lipomas with dysphagia and dyspnea apart from speech and chewing problems depending on size and anatomical location [10] [11]. In this case, the patient had noticed the swelling of the left cheek eight years previously but had not consulted. However, she developed difficulties with chewing and speaking, which led to her seeking treatment. According to Park $\mathrm{BG}$ et al, the time during which the patient notices a lipoma to see a doctor varies from 1 month to 10 years, with an average of 2 years [12]. It is the indolence and lack of functional impairment that are at the origin of such impressive tumors encountered so far in our underdeveloped countries. A similar CT scan has been reported [13] with the addition of an extension towards the right parapharyngeal space causing narrowing of the airways at this level. If the tumor engulfs the Stenon duct, it may be symptomatic, leading to recurrent parotid sialadenitis [14]. In our patient the Stenon canal was not swallowed up; however, the left parotid gland was pushed back.

Histologically, lipomas consist of mature adipocytes grouped together in bundles with a clear cytoplasm and an eccentric nucleus separated by connective septa [15]. Although rare, malignant transformation of the lipoma has also been reported [16]. The pathological result, in our case, is in favor of a simple lipoma.

The treatment of choice for lipoma is surgical excision; however, removal can be difficult in situations if they are positioned deep [17], or the hidden part of the iceberg, represented by fatty extensions in the deep spaces of the face. In our patient, the excision was laborious because of the extensions at the level of the pterygomaxillary, pterygopalatine, and infra-temporal fossae. In plastic surgery, liposuction is mainly used for large lipomas $(\varnothing>4 \mathrm{~cm}$ ) with superficial localization [18]. The advantages of this technique are as follows: the patients are satisfied due to the limited postoperative complications and the esthetic results are excellent, due to the minimal scarring. However, this technique finds its limits when it comes to excising fibroid lipomas, as it often results in incomplete excision of the tumor [19].

Recurrences or complications after surgical removal are rare [12] as also observed in the present case at 45 days of follow-up with good speech, conversation, and chewing.

\section{Conclusion}

Lipomas are benign, painless, slow-growing, ubiquitous tumors, but their oral 
location is rare. Depending on their size, they can cause aesthetic and/or functional problems. Surgical excision remains the treatment of choice for this lesion.

\section{Conflicts of Interest}

The authors declare no conflicts of interest regarding the publication of this paper.

\section{References}

[1] Basheer, S., Abraham, J., Shameena, P., et al. (2013) Intraosseous Lipoma of Mandible Presenting as a Swelling. Journal of Oral and Maxillofacial Pathology, 17, 126128. https://doi.org/10.4103/0973-029X.110705

[2] Bataineh, A.B., Mansour, M.J. and Abalkhail A. (1996) Oral Infiltrating Lipomas. British Journal of Oral and Maxillofacial Surgery, 34, 520-523. https://doi.org/10.1016/S0266-4356(96)90249-1

[3] Kumar, L.K.S., Kurien, N.M., Raghavan, V.B., et al. (2014) Intraoral Lipoma: A Case Report. Case Reports in Medicine, 2014, Artice ID: 480130. https://doi.org/10.1155/2014/480130

[4] Pindborg, J.J. (1985) Benign neoplasm of the oral cavity. In: Pindborg, J.J., Ed., Atlas of Diseases of the Oral Mucosa, Munksgaard, Copenhagen, Denmark, 108 p.

[5] Daryani, D. and Gopakumar, R.A. (2015) Large Oral Lipoma in a Young Patient: A Rare Combination. Contemporary Clinical Dentistry, 25, 236-239. https://doi.org/10.4103/0976-237X.132363

[6] Mehendirratta, M., Jain, K., Kumra, M., et al. (2016) Lipoma of Mandibular Buccal Vestibule: A Case with Histopathological Literature Review. BMJ Case Reports, 2016. https://doi.org/10.1136/bcr-2016-215586

[7] Egido-Moreno, S., Lozano-Porras, A.B., Mishra, S., et al. (2016) Intraoral Lipomas: Review of Literature and Report of Two Clinical Cases. Journal of Clinical and EXperimental Dentistry, 8, 597-603. https://doi.org/10.4317/jced.52926

[8] Furlong, M.A., Fanburg-Smith, J.C. and Childers, E.L.B. (2004) Lipoma of the Oral and Maxillofacial Region: Site and Subclassification of 125 Cases. Oral Surgery, Oral Medicine, Oral Pathology, Oral Radiology, 98, 441-450. https://doi.org/10.1016/j.tripleo.2004.02.071

[9] Shahi, A., Ash, H., Chatterji, K. and Singh, R. (2014) Cellular Infiltrative Angiolipoma of Cheek in an Infant. National Journal of Maxillofacial Surgery, 5, 202-205. https://doi.org/10.4103/0975-5950.154837

[10] Damghani, M.A. and Safari, M. (2015) Huge Tongue Lipoma: A Case Report. Iranian Journal of Otorhinolaryngology, 27, 165-169.

[11] Sharma, G., Jain, K., Nagpal, A., et al. (2016) A Rare Presentation of Lipoma on Mandibular Mucogingival Junction. Journal of Indian Society of Periodontology, 20, 199-202.

[12] Park, B.G., Choi, D.J., Park, J.W., et al. (2015) Oral Cavity Lipoma: A Case Report. Journal of the Korean Association of Oral and Maxillofacial Surgeons, 41, 213-216. https://doi.org/10.5125/jkaoms.2015.41.4.213

[13] Salvatore, C., Antonio, B., Vecchio, W.D., et al. (2003) Giant Infiltrating Lipoma of the Face: CT and MR Imaging Findings. Case Report. American Journal of Neuroradiology, 24, 283-286. 
[14] Tom, O. and Tom, O. (2016) Lipoma of the Cheek Presenting with Recurrent Sialadenitis of the Right Parotid Gland: A Case Report. Journal of Medical Case Reports, 10, Article No. 311. https://doi.org/10.1186/s13256-016-1099-9

[15] Studart-Soares, E.C., Costa, F.W.G., Sousa, F.B., et al. (2010) Oral Lipomas in a Brazilian Population: A 10-Year Study and Analysis of 450 Cases Reported in the Literature. Medicina Oral, Patología Oral y Cirugía Bucal, 15, 691-696.

https://doi.org/10.4317/medoral.15.e691

[16] Silistreli, O.K., Durmuş, E.U., Ulusal, B.G., et al. (2005) What Should be the Treatment Modality in Giant Cutaneous Lipomas? Review of the Literature and Report of 4 Cases. British Journal of Plastic Surgery, 58, 394-398.

https://doi.org/10.1016/j.bjps.2004.09.005

[17] Alharbi, A.S. (2020) Intraoral Lipoma of the Cheek-A Case Report with a OneYear Follow-Up and Review of Literature. Cureus, 12, Article ID: e10537. https://doi.org/10.7759/cureus.10537

[18] Al-basti, H.A. and El-Khatib, H.A. (2002) The Use of Suction-Assisted Surgical Extraction of Moderate and Large Lipomas: Long-Term Follow-Up. Aesthetic Plastic Surgery, 26, 114-117. https://doi.org/10.1007/s00266-002-1492-1

[19] Gupta, S., Pandhi, R. and Kumar, B. (2001) "Pot-Lid" Technique for Aesthetic Removal of Small Lipoma on the Face. International Journal of Dermatology, 40, 420424. https://doi.org/10.1046/j.1365-4362.2001.01225.x 